\title{
Transumbilical laparoendoscopic single-site adrenalectomy: A feasible and safe alternative to standard laparoscopy
}

\author{
João André Carvalho ${ }^{1,2}$, Pedro Tiago Nunes ${ }^{1,2}$, Hugo Antunes ${ }^{1}$, Belmiro Parada ${ }^{1,2}$, \\ Edson Retroz ${ }^{1}$, Edgar Tavares-da-Silva ${ }^{1,2}$, Isabel Paiva ${ }^{3}$, Arnaldo José Figueiredo ${ }^{1,2}$ \\ ${ }^{1}$ Urology and Renal Transplantation Department, Coimbra University Hospital Center, Portugal; \\ ${ }^{2}$ Faculty of Medicine, University of Coimbra; 3. Endocrinology Department, Coimbra University Hospital Center, Portugal.
}

\begin{abstract}
Summary $\quad$ Objectives: Standard multi-port laparoscopic adrenalectomy (LA) is considered the gold standard for benign adrenal tumors. Single-site LA has been proposed as a feasible and safe alternative because of lower invasiveness, improved cosmetics, less pain and shorter hospital stay. The objective was to evaluate and compare results of single-site transumbilical laparoendoscopic adrenalectomy with standard LA for adrenal tumors.

Materials and methods: One hundred consecutive adrenalectomies from 93 patients, performed between March 2009 and June 2017, were laparoscopically excised: 59 by standard multi-port LA (group 1) and 41 by transumbilical laparoendoscopic single-site adrenalectomy (group 2). Data gathered included demographics, comorbidities, preoperative imaging, tumor characteristics, perioperative data, surgical complications, pathology and follow-up. IBM SPSS Statistics 23 software was used and $p$ value $<0.05$ was considered significant. Results: Patients of group 2 were younger ( $48.7 \pm 13.9$ versus $59.7 \pm 15.1$ years; $p<0.001)$ and had fewer comorbidities $(p<0.05)$. Mean tumor diameter in group 2 was lower than those of group $1(27.52 \pm 14.3$ versus $47.9 \pm 30.6 \mathrm{~mm}$; $p<0.001)$. Tumor laterality did not influence the choice of technique nor the surgical morbidity. All procedures were successfully completed, although one standard LA needed conversion to open surgery. Mean operative time, hemorrhagic losses, postoperative opioid analgesic requirement and hospital stay were not statistically different between groups. Most patients in group 2 (31 patients, 85.4\%) did not require drainage, compared to $14(25.4 \%)$ patients of group $1(p<0.001)$. Patients who underwent single-site $L A$ resumed normal diet earlier $(1.0 \pm 0.2$ versus $1.6 \pm 0.7$ days; $p<0.001)$. There were no reoperations and no perioperative mortality. Overall mean follow-up time was $94.9 \pm 3.1$ months, not statiscally different between groups $(p=0.7)$.

Conclusions: Our results revealed that transumbilical approach for laparoendoscopic single-site adrenalectomy for adrenal tumors is a feasible and safe alternative to standard laparoscopic adrenalectomy.
\end{abstract}

KEY WORDS: Standard multi-port laparoscopic adrenalectomy; Laparoendoscopic single-site surgery: Partial adrenalectomy.

Submitted 26 August 2018; Accepted 3 September 2018

\section{INTRODUCTION}

The first laparoscopic adrenalectomy was performed by Gagner et al. (1) in 1992 and, since then, it has become the gold standard procedure for most adrenal tumors.
Standard multiport laparoscopic adrenalectomy (LA) involves the use of typically three to five ports, depending on the complexity of the procedure. Nowadays, laparo-endoscopic single-site surgery (LESS) is exciting the scientific community because it offers the opportunity to do major laparoscopic surgery with no visible scars and with potential reduced postoperative pain and hospital stay (2). LESS has been used for cholecystectomy (3), appendectomy (4) and several urological surgeries (5), but the high degree of difficulty and the longer learning curve tends to make its widespread difficult. LESS surgery through the umbilicus is the most appealing approach, as it truly avoids any new scar, with the multichannel port being placed through a 1.5 to $2 \mathrm{~cm}$ incision at the deep edge of the obliterated embryonic orifice. Partial adrenalectomy has been a promising surgical technique mainly in functioning lesion in a solitary adrenal gland or in bilateral hereditary or sporadic tumors with the goal of reducing endocrinopathy. However, it has a relapse risk that we always have to remember (6).

Here, we present our experience with transumbilical LESS adrenalectomy comparing with standard multiport laparoscopic multiport, showing our results with partial adrenalectomy too.

\section{Material AND Methods}

Between March 2009 and June 2017, 100 adrenal glands from 93 patients underwent transperitoneal laparoscopic adrenalectomy at the Urology and Renal Transplantation Department of Coimbra University Hospital Center: 59 (59\%) underwent standard multi-port laparoscopy (group 1) and 41 (41\%) underwent transumbilical laparo-endoscopic single-site adrenalectomy (group 2). Standard multi-port laparoscopy included three to four ports. The multichannel port (Triport) and bent laparoscopic instruments were supplied by Olympus Surgical (KeyMed House, Stock Road, United Kingdom).

The multichannel port was placed through a $2-\mathrm{cm}$ incision at the inner edge of the umbilicus and a bent instrument on the left hand was used to create the operative angle. In 30\% of cases, it was needed a forceps with no port to move the liver away from the operative field. All transumbilical laparoendoscopic single-site adrenalec- 
tomies were executed by one surgeon while standard LA were performed by more than one surgeon. Data gathered included demographics, comorbidities, preoperative imaging, tumor characteristics, perioperative data, surgical complications, length of stay, need for analgesia, pathology and follow-up. All patients were evaluated by the Endocrinology team with a standard protocol. Written informed consent was obtained from all patients and the study was performed according to the Declaration of Helsinki. Data were collected retrospectively and processed with IBM SPSS Statistics 23 software. Groups were compared using the chi-square test and $t$ Student test for categorical and continuous variables, respectively. Survival analysis was done through Kaplan-Meyer survival curve. Statistical significance was set at $p$ value of $<0.05$, and all reported $\mathrm{p}$-values are two-sided.

\section{RESULTS}

Patient demographic data are shown in Table 1. Patients elected for transumbilical LESS adrenalectomy were younger and with less comorbidities.

Preoperative tumor data are shown at Table 2. The laterality of the lesion didn't have any impact in the choice of the surgical technique. $52.5 \%$ of the cases submitted to standard multi-port LA were incidentally diagnosed nonfunctioning enlarged adrenals. In group 2, arterial hypertension was the main initial symptom and elevated aldosterone was the most common finding. Only $24.4 \%$ of the tumors submitted to transumbilical LESS adrenalectomy were non-functioning.

Perioperative data are shown in Table 3. There was no difference between groups concerning operative time and estimated blood loss. 29.3\% of transumbilical LESS surgeries were partial adrenalectomies: no one was done by standard multi-port laparoscopy. Seven (7\%) patients were submitted to bilateral adrenalectomies, two by multi-port LA and five by transumbilical LESS technique. Drainage was placed in a minority of cases submitted to transumbilical LESS technique while the majority of patients submitted to standard multi-port laparoscopy underwent drainage placement. One case of multi-port LA was converted to open surgery due to the

\section{Table 1.}

Demography and comorbities between groups.

Group 1: patients submitted to standard multi-port laparoscopy adrenalectomy.

Group 2: patients submitted to transumbilical approach for laparoendoscopic single-site adrenalectomy.

\begin{tabular}{|lccc|}
\hline Demographic data & Group 1 & Group 2 & P-value \\
\hline Patients $(\mathrm{n})$ & $57(61.3 \%)$ & $36(38.7 \%)$ & \\
\hline Number of adrenal glands & $59(59 \%)$ & $41(41 \%)$ & \\
\hline Age at surgery (years) & $59.7 \pm 15.1$ & $48.7 \pm 13.9$ & $\mathrm{p}<0.001$ \\
\hline Sex & $39.0 \%$ & $36.6 \%$ & NS (p: 0.8) \\
$\quad$ Male & $61.0 \%$ & $63.4 \%$ & \\
$\quad$ Female & $20.3 \%$ & $2.4 \%$ & p: 0.013 \\
\hline Cardiovascular disease & $27.1 \%$ & $7.3 \%$ & p: 0.02 \\
\hline Diabetes mellitus type 2 & & & \\
\hline NS: Non-significant. & & & \\
\hline
\end{tabular}

Table 2.

Preoperative tumour data between groups.

Group 1: patients submitted to standard multi-port laparoscopy adrenalectomy.

Group 2: patients submitted to transumbilical approach for laparoendoscopic single-site adrenalectomy.

\begin{tabular}{|c|c|c|c|}
\hline Tumor data & $\begin{array}{l}\text { Group 1 } \\
(n=57)\end{array}$ & $\begin{array}{c}\text { Group 2 } \\
(n=36)\end{array}$ & P-value \\
\hline Laterality & & & NS (p: 0.6) \\
\hline Left & $61.0 \%$ & $61.0 \%$ & \\
\hline Right & $39.0 \%$ & $39.0 \%$ & \\
\hline Presentation & & & p: 0.02 \\
\hline Incidental & $52.5 \%$ & $31.7 \%$ & \\
\hline Arterial hypertension & $35.6 \%$ & $39.0 \%$ & \\
\hline Cushing disease & $5.1 \%$ & $24.4 \%$ & \\
\hline Metastasis & $0 \%$ & $2.4 \%$ & \\
\hline Pain & $6.8 \%$ & $2.4 \%$ & \\
\hline Functioning adenoma & & & p: 0.01 \\
\hline Yes & $50.8 \%$ & $75.6 \%$ & \\
\hline No & $49.2 \%$ & $24.4 \%$ & \\
\hline Produced hormone & & & p: 0.002 \\
\hline Non-functioning & $49.2 \%$ & $24.4 \%$ & \\
\hline Aldosterone & $11.9 \%$ & $34.1 \%$ & \\
\hline Catecholamines & $28.8 \%$ & $14.6 \%$ & \\
\hline Cortisol & $8.5 \%$ & $26.8 \%$ & \\
\hline DHEA & $1.7 \%$ & $0 \%$ & \\
\hline Mean imaging diameter on $\mathrm{CT}(\mathrm{mm})$ & $47.9 \pm 30.6$ & $27.52 \pm 14.3$ & $p<0.001$ \\
\hline Mean imaging diameter on $\mathrm{CT}>40 \mathrm{~mm}$ & $56.4 \%$ & $15.2 \%$ & $p<0.001$ \\
\hline Maximum diameter (mm) & 120 & 80 & \\
\hline
\end{tabular}

\section{Table 3.}

Comparison of perioperative data between groups.

Group 1: patients submitted to standard multi-port laparoscopy adrenalectomy.

Group 2: patients submitted to transumbilical approach for laparoendoscopic single-site adrenalectomy.

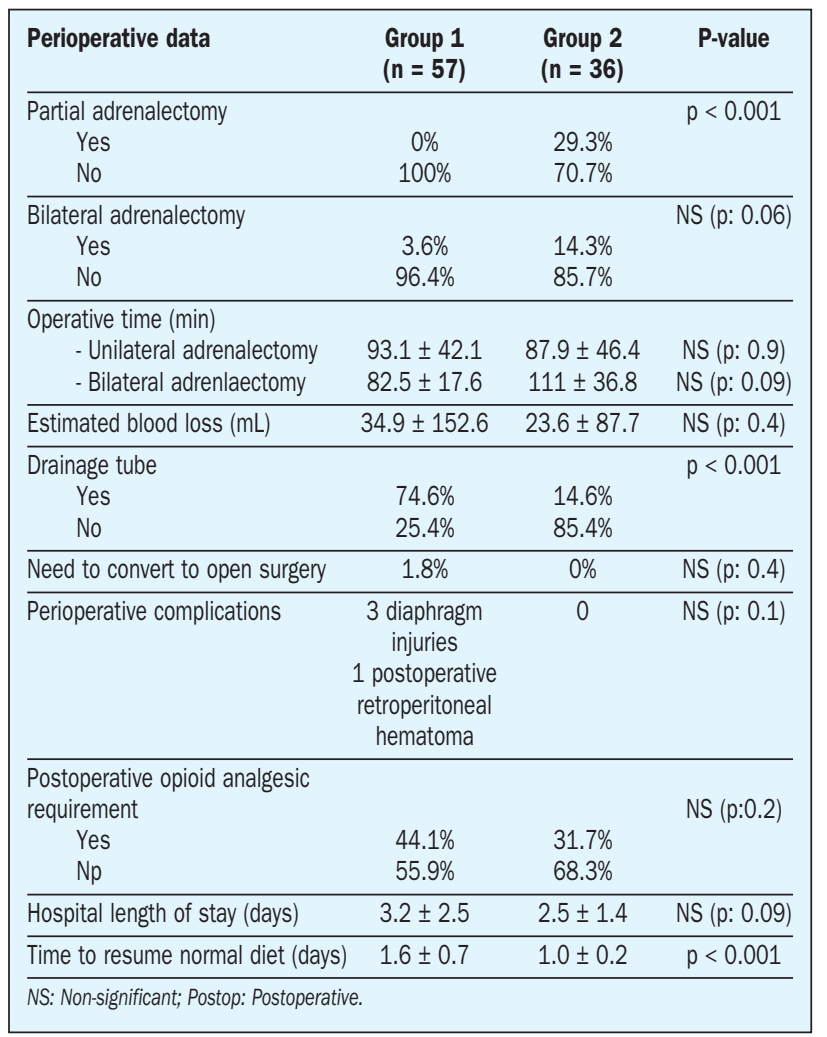


Table 4.

Pathological data between groups.

Group 1: patients submitted to standard multi-port laparoscopy adrenalectomy.

Group 2: patients submitted to transumbilical approach for laparoendoscopic single-site adrenalectomy.

\begin{tabular}{|lccc|}
\hline Tumor data & Group 1 & Group 2 & P-value \\
\hline Mean pathological diameter (mm) & $42.4 \pm 27.2$ & $26.50 \pm 16.3$ & $\mathrm{p}<0.001$ \\
\hline Adenoma & $41.4 \%$ & $48.8 \%$ & $\mathrm{p:} 0.04$ \\
Benign pheochrom cytoma & $20.7 \%$ & $12.2 \%$ & \\
Malignant pheochromcytoma & $6.9 \%$ & $2.4 \%$ & \\
Intermediate pheochromcytoma & $1.7 \%$ & $2.4 \%$ & \\
Cortical hyperplasia & $0 \%$ & $17.1 \%$ & \\
Carcinoma & $10.3 \%$ & $4.9 \%$ & \\
Myelolipoma & $6.9 \%$ & $0 \%$ & \\
Metastatic lesion ab initio & $1.7 \%$ & $4.9 \%$ & \\
Ganglioneuroma & $0 \%$ & $2.4 \%$ & \\
Cavernous hemangioma & $1.7 \%$ & $0 \%$ & \\
Cyst & $3.4 \%$ & $0 \%$ & \\
Undetermined & $5.2 \%$ & $4.9 \%$ & \\
\hline
\end{tabular}

Table 5.

Characteristics of the tumours submitted to transumbilical partial LESS adrenalectomy.

\begin{tabular}{|c|c|}
\hline Tumor data & Value \\
\hline $\mathrm{N}$ & 9 \\
\hline \multicolumn{2}{|l|}{ Laterality } \\
\hline Left & $41.7 \%$ \\
\hline Right & $58.3 \%$ \\
\hline \multicolumn{2}{|l|}{ Bilateral } \\
\hline Yes & $55.6 \%$ \\
\hline No & $44.4 \%$ \\
\hline \multicolumn{2}{|l|}{ Presentation } \\
\hline Cushing disease & $41.7 \%$ \\
\hline Arterial hypertension & $33.3 \%$ \\
\hline Incidental & $25 \%$ \\
\hline \multicolumn{2}{|l|}{ Functioning adenoma } \\
\hline Yes & $100 \%$ \\
\hline No & $0 \%$ \\
\hline \multicolumn{2}{|l|}{ Produced hormone } \\
\hline Cortisol & $58.3 \%$ \\
\hline Aldosterone & $41.7 \%$ \\
\hline Mean Imaging diameter on CT (mm) & $21.8 \pm 10.3$ \\
\hline Mean Imaging diameter on CT > 40 mm & $0 \%$ \\
\hline \multicolumn{2}{|l|}{ Pathological data } \\
\hline Adenoma & $50 \%$ \\
\hline Cortical hyperplasia & $41.7 \%$ \\
\hline Unknown cause & $8.3 \%$ \\
\hline Operative time (minutes) & $100.4 \pm 31.3$ \\
\hline Hemorragic losses $<200$ cc & $100 \%$ \\
\hline Need of drainage & $25 \%$ \\
\hline Resume to normal diet (days) & $1 \pm 0.1$ \\
\hline Hospital length of stay (days) & $2.8 \pm 1.4$ \\
\hline Reoperation; Perioperative complications; Relapse & 0 \\
\hline Improved or normalized arterial pressure & $88.8 \%$ \\
\hline Postoperative need for replacement medical therapy & $16.7 \%$ \\
\hline Follow-up (months) & $17.4 \pm 10.6$ \\
\hline
\end{tabular}

absence of surgical plans in a lesion that revealed to be posteriorly a melanoma metastasis. There were four perioperative complications, all of them during or after a standard multi-port laparoscopic adrenalectomy. There was no difference concerning postoperative opioid analgesic requirement and hospital length of stay. The hospi-
Figure 1.

Survival curves between groups.

Group 1: patients submitted to standard multi-port laparoscopy adrenalectomy.

Group 2: patients submitted to transumbilical approach for laparoendoscopic single-site adrenalectomy.

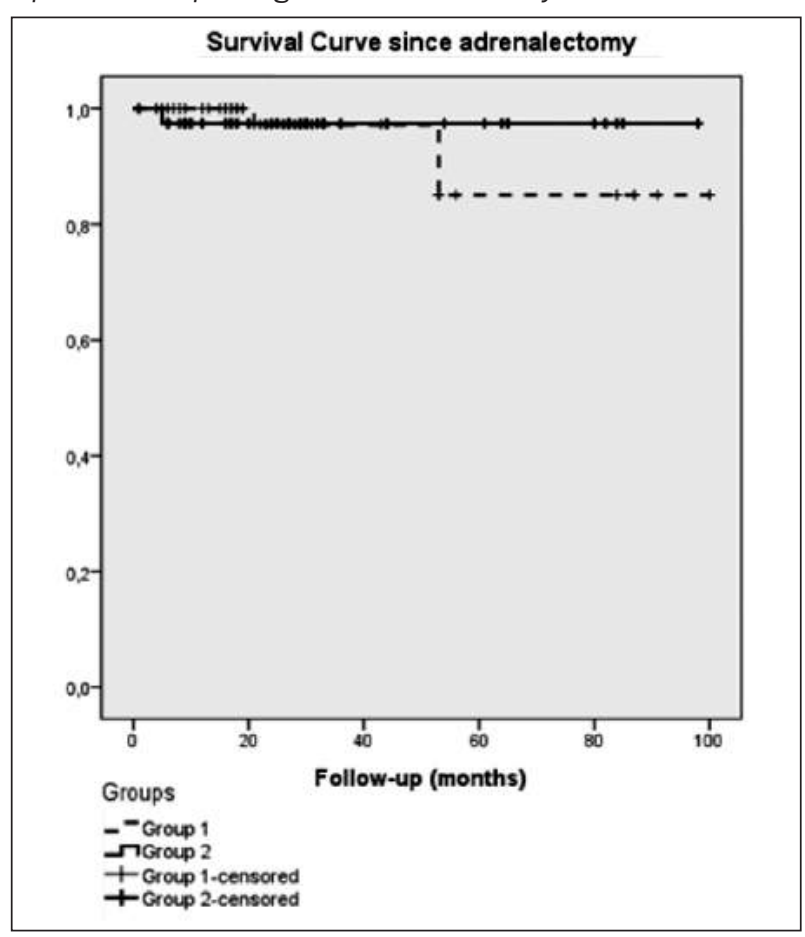

tal length of stay was mainly conditioned by medical or hormonal issues more than the surgery itself. However, the time to resume normal diet was lower in group 2. There were neither reoperations nor perioperative mortality and the tumor laterality did not influence surgical morbidity ( $p>0.05)$.

Transumbilical LESS technique allowed for a completely hidden scar in all cases, with excellent cosmesis.

The final pathology is shown in Table 4. The mean pathological diameter was inferior in the group 2 and, in both groups, benign adenoma was the most common diagnosis. In the next table (Table 5), there is a brief summary on our experience with partial adrenalectomy. All of them were submitted to transumbilical LESS technique and all lesions were hormone producing. More than half were bilateral and presented mostly with symptoms of Cushing disease and arterial hypertension. The pathological data revealed mainly adenoma and cortical hyperplasia.

Overall mean follow-up time was $94.9 \pm 3.1$ months (group $1=92.1 \pm 5.7$ months versus group $2=95.6 \pm$ 2.4 months with no statistically difference between groups, $\mathrm{p}=0.7$ ), as shown in Figure 1 .

\section{Discussion}

Laparoendoscopic single-site adrenalectomy is a minimally invasive surgical technique that is being increasingly used. Transumbilical route offers the opportunity to remove the adrenal gland or only the adrenal tumor with only one hidden incision. Therefore, the level of patient with the scar cosmetics is expected to be better. 
Wang et al. (7) concluded that laparoendoscopic single-site adrenalectomy caused less postoperative pain, albeit, requiring a longer surgical time (55-206 minutes). Other positive factors in favor of laparoendoscopic single-site adrenalectomy are reduced length of hospital stay and improved postoperative aesthetics (8). Jeong et al. (9) compared transumbilical LESS with standard LA to remove a benign adrenal adenoma and concluded that there were no differences concerning operative time, estimated blood loss and hospital stay but the sample was only nine patients.

Our results showed that transumbilical approach for laparoendoscopic single-site adrenalectomy for adrenal tumors is a feasible and safe alternative to standard laparoscopic adrenalectomy: operative time, hemorrhagic losses, postoperative opioid analgesic requirement and hospital stay were similar, yet normal diet was resumed earlier. More standard LA cases were drained, but this difference to transumbilical LESS may have been promoted by a stronger focus on cosmetics.

The coordination between the surgeon and assistant is vital for this procedure to avoid clashing of instruments with the camera: for that reason, bent instruments were used for the left surgeon hand, along with a flexible camera. Operative time was the same for the two techniques, but patient selection could be a bias to the analysis: patients submitted to laparoendoscopic single-site adrenalectomy were typically younger, with less comorbidities and with lesions of adrenal gland with a smaller diameter. The rate of perioperative complications and the need for conversion to open surgery was zero in the laparoendoscopic single-site adrenalectomy and only one case of the standard multi-port laparoscopic adrenalectomy need conversion due to absence of surgical safer plans. Again, patient selection is extremely important to choose the laparoscopic approach instead of the open approach.

The high degree of difficulty and the alleged longer surgical learning curve makes this surgical approach only feasible for experienced laparoscopic surgeons. In our institution, a single urologist performed the transumbilical laparoendoscopic single-site adrenalectomies and standard laparoscopic adrenalectomies were executed by several urologists. The reduced drainage need and the faster recovery of normal diet in transumbilical LESS adrenalectomies could be biased for that reason.

LESS approach can be implemented in partial adrenalectomy (10). We started to do partial adrenalectomy and all of them were done by transumbilical LESS technique and all were hormonal active adrenal tumors. During the last years, partial adrenalectomy has been accepted for adrenal tumors in unilateral glands or in patients with hereditary syndromes. Our experience is limited, the follow-up is short to see if there is any relapse and only two patients are not corticoid-free of medical therapy. Partial adrenalectomy is especially done in Conn's syndrome and in pheochromocytoma. In our series, no pheochromocytoma was submitted to partial adrenalectomy probably because of the multifocal nature of the disease that could explain the relatively high recurrence rate in hereditary pheochromocytoma (10) and for that reason we did not perform partial adrenalectomies in these patients. Nagaraja et al. (6) found that the overall recurrence rate was 8\% and 85\% of the patients were steroid-free. In our series, no relapse was found and $83.3 \%$ of patients did not need any substitutive therapeutic after surgery. More experience and more time are needed to evaluate if this technique could be a good alternative to total adrenalectomy. Although LESS partial adrenalectomy may be a well-tolerated and feasible procedure to reduce endocrinopathy, studies proving long-term outcome and controlled trials are missing: earlier publications suggested that only one-third of one gland is sufficient to avoid hormonal deficiency (6).

\section{Conclusions}

Transumbilical approach for laparoendoscopic single-site adrenalectomy for adrenal tumours could be a good alternative to standard laparoscopic adrenalectomy. Our results showed similar perioperative data, less drainage, quicker return to normal diet and with no reoperations or perioperative mortality.

\section{REFERENCES}

1. Gagner M, Lacroix A, Bolté E. Laparoscopic adrenalectomy in Cushing's syndrome and pheochromocytoma. N Engl J Med. 1992; 327:1033-1033

2. Miyajima A, Hattori S, Maeda T, et al. Transumbilical approach for laparo-endoscopic single-site adrenalectomy: initial experience and short-term outcome. Int J Urol. 2012; 19:331-5.

3. Piskun G, Rajpal S. Transumbilical laparoscopic cholecystectomy utilizes no incisions outside the umbilicus. J. Laparoendosc. Adv Surg Tech. A 1999; 9:361-4.

4. Esposito C. One-trocar appendectomy in pediatric surgery. Surg Endosc. 1998; 12:177-8.

5. Aron M, Canes D, Desai MM, et al. Transumbilical single-port laparoscopic partial nephrectomy. BJU Int. 2009; 103:516-21.

6. Colleselli D, Janetschek G. Current trends in partial adrenalectomy. Curr Opin Urol. 2015; 25:89-94.

7. Wang $L, W u Z$, Li M, et al. Laproendoscopic single-site adrenalectomy versus conventional lapartoscopic surgery: a systematic review and meta-analysis of observational studies. J Endourol. 2013; 27:743-750.

8. Lal G, Duh QY. Laparoscopic Adrenalectomy - Indications and technique. Surg Oncol. 2003; 12:105-123.

9. Jeong BC, Park YH, Han DH, et al. Laparoendoscopic single-site and conventional laparoscopic adrenalectomy: a matched case-control study. J Endourol. 2009; 23:1957-60.

10. Ho CH, Liao PW, Lin VC, et al. Laparoendoscopic single-site (LESS) retroperitoneal partial adrenalectomy using a custom-made single-access platform and standard laparoscopic instruments: technical considerations and surgical outcomes. Asian J Surg. 2015; 38:6-12.

\section{Correspondence}

João André Carvalho, MD (Correspondence Author)

joao.andre.mendes.carvalho@gmail.com

Rua Paulo Quintela, Lote 6,7º, 3030-393 Coimbra (Portugal)

Pedro Tiago Nunes, MD - ptnunes@gmail.com

Hugo Antunes, MD - hugoantunes4@gmail.com

Belmiro Parada, MD - parada.belmiro@gmail.com

Edson Retroz, MD - edson.retroz@gmail.com

Edgar Tavares-da-Silva, MD - edsilva.elv@gmail.com

Isabel Paiva, MD - ipaiva@netcabo.pt

Arnaldo José Figueiredo, MD - ajcfigueiredo@gmail.com

Praceta Prof. Mota Pinto 3000-075 Coimbra (Portugal) 